\title{
Design and Analysis of Air Distributors and Bed Materials of Fluidized Bed Boiler
}

\author{
Ishan Kafle*, Sajesh Bhochhibhoya, Lokesh Paudel, Pradeep Parajuli, Sojan Prajapati, \\ Pratisthit Lal Shrestha
}

Department of Mechanical Engineering, Kathmandu University, Dhulikhel, Kavre, Nepal

\section{Email address:}

kafleishan@gmail.com (I. Kafle),7sajesh@gmail.com (S. Bhochhibhoya), paudellokesh08@gmail.com (L. Paudel), pra_deep_ppt@yahoo.com (P.Parajuli),prajapatisojan@gmail.com (S. Prajapati), pratisthit@ku.edu.np (P. L. Shrestha)

${ }^{*}$ Corresponding author

\section{To cite this article:}

Ishan Kafle, Sajesh Bhochhibhoya, Lokesh Paudel, Pradeep Parajuli, Sojan Prajapati, Pratisthit Lal Shrestha. Design and Analysis of Air Distributors and Bed Materials of Fluidized Bed Boiler. International Journal of Fluid Mechanics \& Thermal Sciences.

Vol. 2, No. 4, 2016, pp. 22-36. doi: 10.11648/j.ijfmts.20160204.11

Received: October 31, 2016; Accepted: December 1, 2016; Published: December 30, 2016

\begin{abstract}
This research deals with the design and analysis of the nozzle and bed materials required for fluidized bed boiler. The design parameters (Diameter of the bed particle, Range of the terminal velocities, Minimum Fluidization /Bubbling velocities, Maximum amplitude and steady velocities) were calculated using Microsoft Excel by interpreting and solving various formulas. Best bed material was selected on the basis of their various characteristics like porosity, adhesive or cohesive properties, resistance to flow etc. An important characteristic change of air distributor velocity with combustion chamber temperature has been established. ANSYS was used as a simulation tool for the analysis. Static Structural solver was used to carry out the strength analysis of the designed wind box. Likewise, computational fluid dynamics (CFD) was carried out using FLUENT solver. Air flow inside the wind box and fluidization phenomena was verified using FLUENT. Furthermore, the designed system was checked for its validity by comparing the results from the Excel sheets and theoretical calculations with simulation results. Lastly, correlation between temperature and velocity inside combustion temperature were determined to identify their relationship with each other.
\end{abstract}

Keywords: CFD, Fluidization, Fluidized Bed Boiler, Wind Box

\section{Introduction}

Coal accounts for one of the major fuels utilized in Nepal and is almost exclusively consumed mainly by industrial sectors for heating and boiling processes in bricks, cement, steel production. Apart from fewer coal reserves, coal for industrial usage is imported from other countries, primarily India. Statistically, only eighteen hundred thousand tons are produced within the country as compared to five hundred and fifty hundred thousand tons that are being imported [1]. Despite this, problem occurred due to low quality, low calorific value and undesirably high ash content in the brought-in coal. It is uneconomical to use such qualities coal in the traditional grate systems. Hence, the concept of fluidized bed combustion has been emerged as a promising alternative in order to address the above issues. It bears substantial advantages over conventional firing system as it offers multiple benefits such as fuel flexibility, higher combustion efficiency, compact boiler design and reduced emission of noxious pollutants such as SOx and NOx [1]. Coal, rice husk and agricultural wastes are burnt in these boilers. These boilers have industrial scale size and are not available in any universities of Nepal. So, there is a need of a design of a laboratory test rig for detail and practical study of "Fluidized bed combustion Boilers". The research is focused in designing a "Circulatory Fluidized Bed Boiler" with the optimum design of air distribution system, selection of suitable bed materials and computational study of movement of bed materials. 


\section{Theory Background}

\subsection{History and Background}

Not quite long ago, on December 16, 1921 Fritz Winkler [3] initiated the process of fluidization i.e. the art of making granular solids behave like a liquid. In early 1960s, Douglas Elliott [4] promoted bubbling fluidized bed using the idea of burning instead of gasifying fuel and focused on the advantages of burning coal in fluidized beds by immersing boiler tubes in it. Lurgi [5] developed an aluminum calcining process based on laboratory-scale work in their Metallgesellschaft laboratories. Calcination, being an endothermic process, burning of gas or oil was required. The combustion heat was recovered in a multistage bubbling fluidized bed cooler, where waste gases exchanged heat with feed materials. This allowed the uniform control of the calcining temperature within required limits with use of the circulating fluidized bed process. Several companies used high-ash coal to engender heat for the calcination of limestone, especially for the pre-calcining stage of the cement clinkering process, thereby demonstrating the efficacy of CFB combustion for utilization of low-grade coal [6].

\subsection{Fluidized Bed Combustion System}

Due to the limitations in conventional grate fuel firing systems and its inability to meet the standards of future techno-economically, there is the need of an alternative that can address this issue and as a result, fluidized bed combustion has evolved as promising one. Its significant advantages over traditional firing system and other multiple benefits like compact boiler design, fuel flexibility, higher combustion efficiency and reduced emission of obnoxious pollutants such as SOx and NOx make it a favorable substitute. In these boilers, the fuels burnt include coal, rice husk, bagasse and other agricultural wastes. Such boilers have a wide capacity range of $0.5 \mathrm{~T} / \mathrm{hr}$ to over $100 \mathrm{~T} / \mathrm{hr}$ [7].

\subsection{Mechanism of Fluidized Bed Combustion}

At first, a uniformly distributed air or gas is passed upward through a finely divided bed of solid particles. At low velocity, the particles remain undisturbed whereas as the velocity is gradually increased, the individual particles become suspended in the air stream and the bed, at this stage, is said to be fluidized. This condition is illustrated in Figure 1. Further increase in air velocity causes the formation of bubbles with vigorous turbulence, rapid mixing and creation of dense defined bed surface. Such bed of solid particles exhibits the properties of a boiling liquid and takes the resemblance of a fluid and is known as bubbling fluidized bed. At higher velocities, these bubbles disappear and particles are blown out of the bed. Consequently, in order to maintain the stability in the system, some amounts of particles have to be recirculated, known as a circulating fluidized bed. Fluidization depends largely on the particle size and the air velocity; as a result, solid velocity increases at a slower rate than the gas velocity. Figure 2 illustrates the slip velocity -the difference between the mean solid velocity and mean gas velocity. For good heat transfer and intimate contact, it is desirable to maintain slip velocity as high as possible.
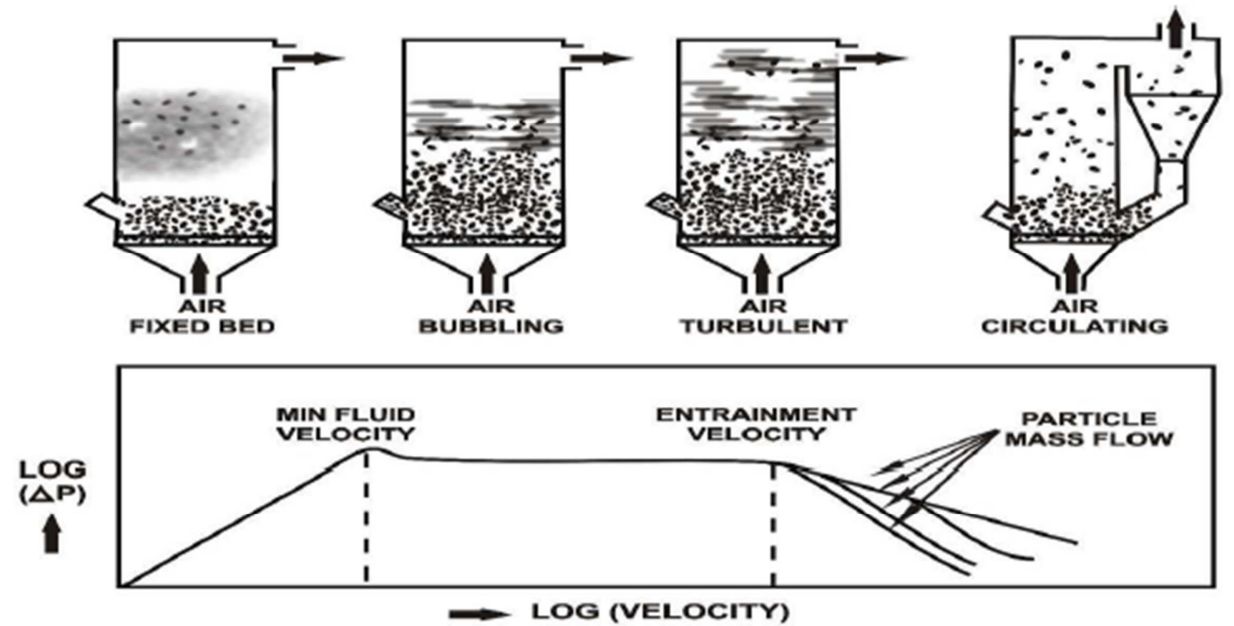

Figure 1. Variation of pressure drop vs Gas Velocity [8].

Once the sand particles in a fluidized state are heated to the ignition temperatures of coal with coal injected into the bed continuously, the coal will burn rapidly and the bed attains a uniform temperature. The fluidized bed combustion (FBC) occurs place at about $840^{\circ} \mathrm{C}$ to $950^{\circ} \mathrm{C}$ temperature [9]. As a result of this temperature being lower than ash fusion temperature, melting of ash and other associated problems are avoided. Combustion process requires the three T's i.e. time, temperature and turbulence. In FBC, fluidization promotes turbulence, improved mixing generates evenly distributed heat at lower temperature and residence time is many times greater than traditional grate firing. Accordingly, an FBC system releases heat more efficiently at lower temperatures. 


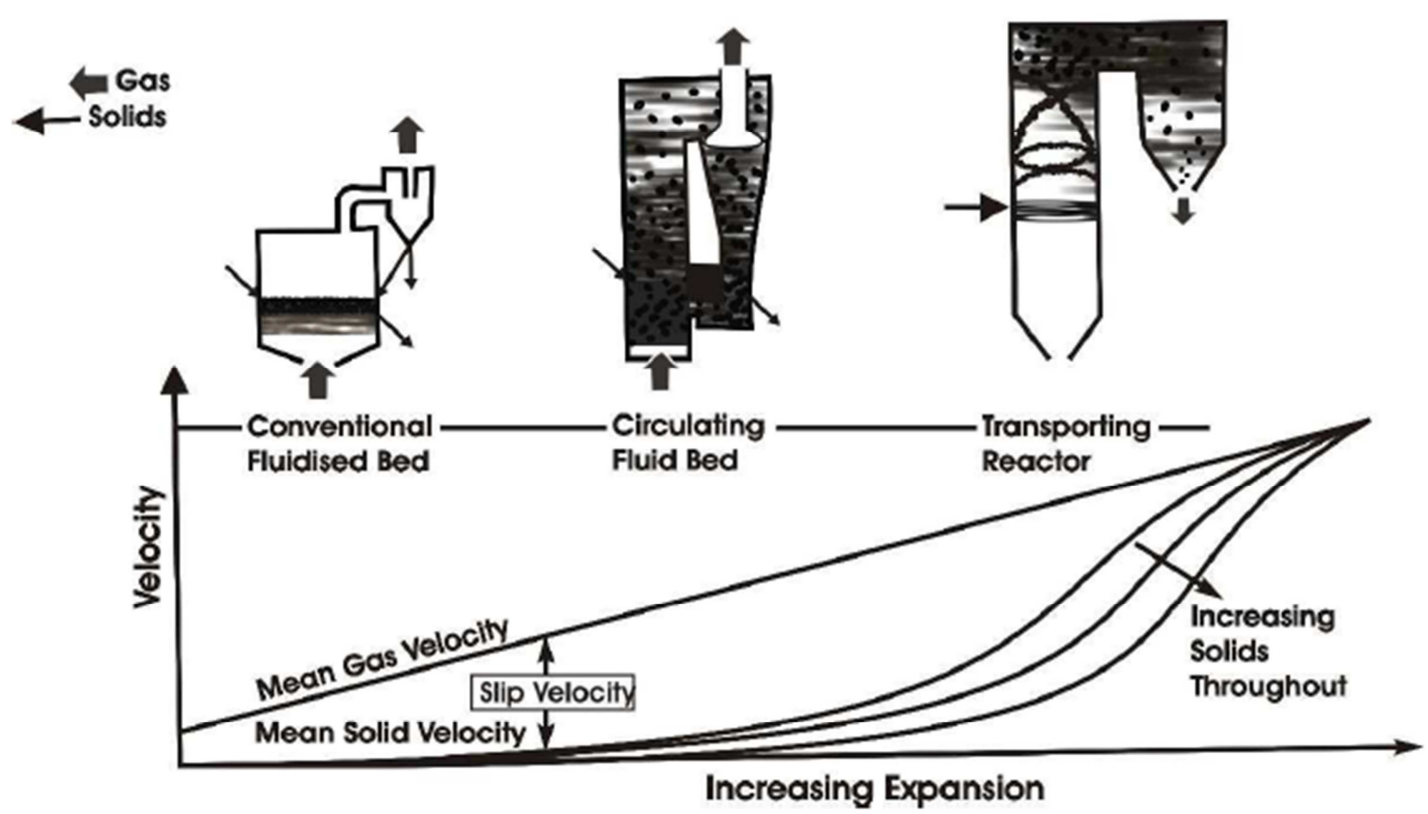

Figure 2. Relation between Gas Velocity and Solid Velocity [8].

\subsection{Circulating Fluidized Bed Combustion System (CFBC)}

Due to the presence of shortcomings in traditional bubbling bed combustion, it is the need of time to develop the Circulating Fluidized Bed Combustion (CFBC) technology with advanced features. In this technology, crushed (6 -12 mm size) fuel and limestone are injected into the furnace and particles remain suspended in a stream of flowing air in upward direction [2]. The velocity in circulating beds remains in between 3.7 to $9 \mathrm{~m} / \mathrm{sec}$. Then, the combustion takes place allowing the fine particles to eliminate out of the furnace with flue gas velocity of 4 to 6 $\mathrm{m} / \mathrm{s}$. Eventually, these particles are collected by the solid separators and circulated back into the furnace. It is desirable to achieve the maximum heat transfer outside the combustion zone, so, the circulating bed is designed to move a lot more solids out of the furnace area.

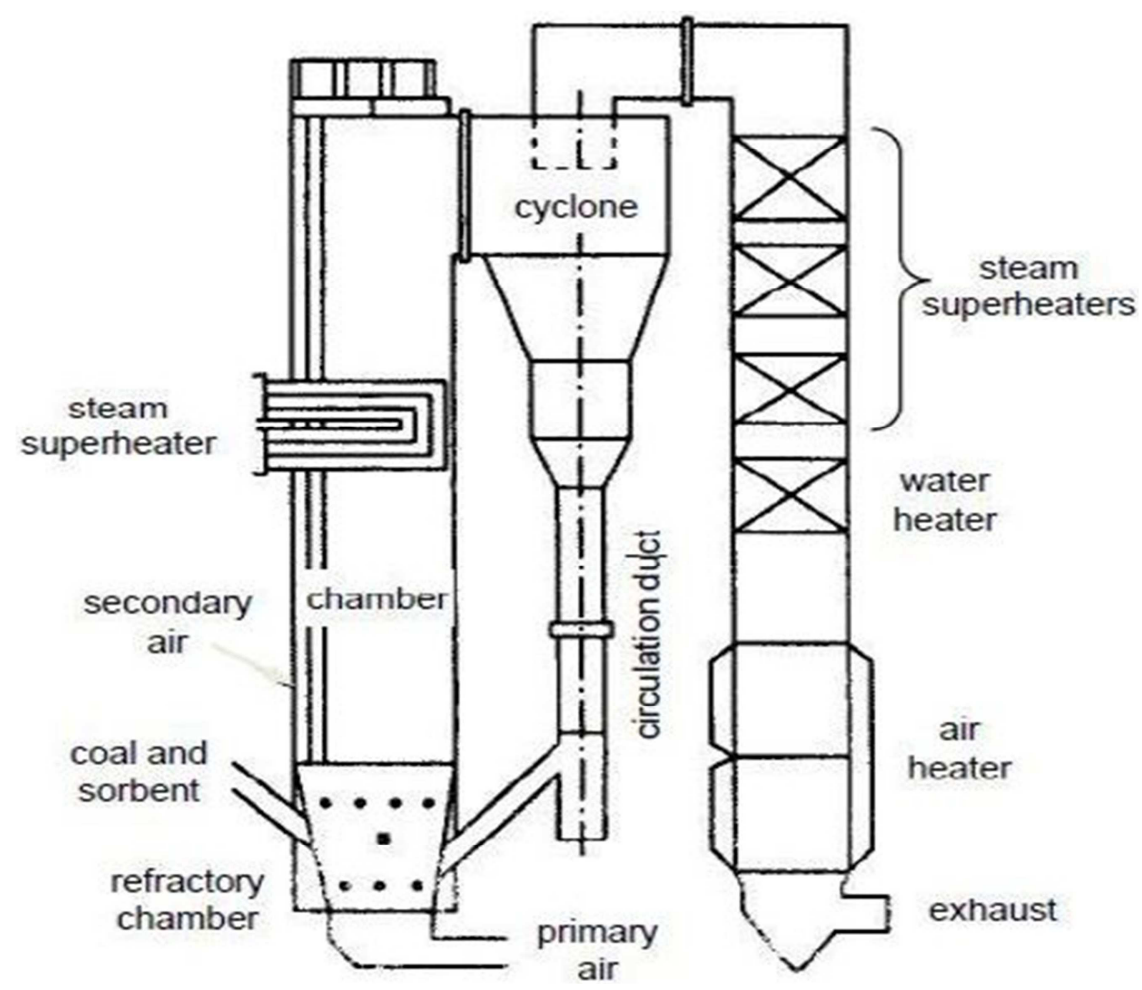

Figure 3. Circulating Bed Boiler Design [2]. 


\subsection{Bed Material Classification}

Certain volume of space within the particles are not occupied and such a space is known as void volume and is specified as voidage or porosity, defined as [10] [11]

Voidage $(\epsilon)=($ void volume $/$ volume of particles + voids $)(1)$
Figure 4 illustrates the broad classification of solids, made by Gelbert (1972) [12] into four different groups, namely A, B, C and D. A graph of particle's classification versus density difference between the solid and the fluidizing gas, is plotted.

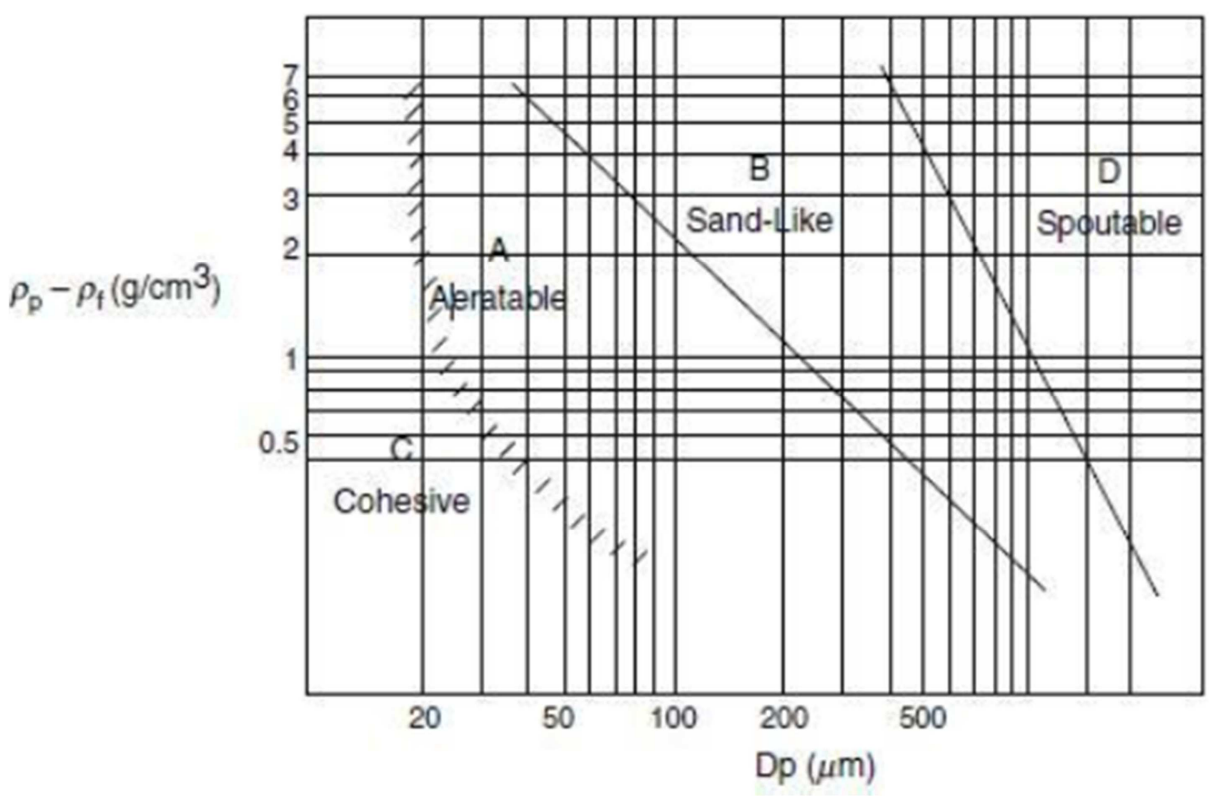

Figure 4. Powder classification developed by Geldart [12].

A comparison of properties of particles of different groups is given in the figure below:

\section{Distinguishing Feature of Four Groups of Particles}

\section{Group}

Particle size for

$\rho_{\rho}=2500 \mathrm{~kg} / \mathrm{m}^{3}$

Channeling

Spoutability

Expansion

Minimum bubbling

velocity, $U_{\mathrm{mb}}$

Bubble shape

Solid mixing

Gas back-mixing

Slugging mode

Effect of particle size

on hydrodynamics
C

$$
<20 \mu \mathrm{m}
$$

Severe

None

Low

No bubble

Only channel

Very low

Very low

Flat raining plugs

Unknown
A

$20-90 \mu \mathrm{m}$

Little

None

High

$>U_{\mathrm{mf}}$

Flat base

spherical cap

High

High

Axisymmetric

Appreciable
B

$90-650 \mu \mathrm{m}$

Rounded with

small indentation

Medium Low

Medium

Mostly axisymmetric

Minor
$>650 \mu \mathrm{m}$

Negligible

Readily

Medium

$=U_{\mathrm{mf}}$

Rounded

D

Low

Mostly wall slugs

Unknown

Figure 5. Features of various group particles [12].

\subsection{Design of the Wind Box}

The wind-box is used to distribute the gas under the distributor as uniformly as possible. The gas stream nozzle enters the gas chamber either horizontally or vertically. For horizontal entry into a vertical vessel, expansion of the high velocity gas stream occurs until following condition arises [12]

1 It hits the opposite wall.

2 It dissipates itself at about 100 times nozzle diameter.

3 The upper edge hits the base of the distributor plate 
causing mal-distribution.

In the third case, so as to prevent mal-distribution, the distributor plate should be placed at a distance $\mathrm{H}$, above the gas nozzle.

Therefore [12],

$$
\begin{gathered}
H_{w}=\left(0.2 \times D_{w}\right)+\left(0.5 \times D_{n o z}\right) ; \text { For } D_{n o z}>\frac{D_{w}}{100} \\
H_{w}=18 \times D_{n o z} ; \text { For } D_{n o z}<\frac{D_{w}}{100}
\end{gathered}
$$

\subsection{Design of Nozzles and Arrangement}

It is often recommended a high pressure drop across the

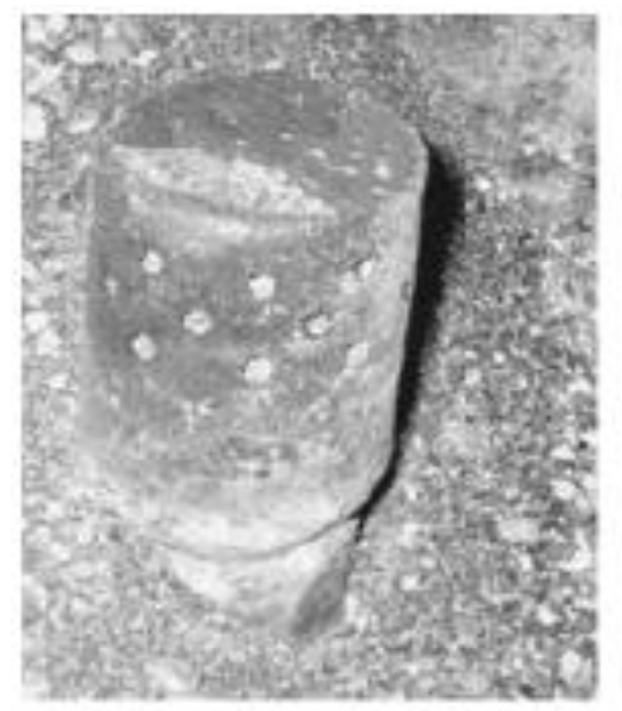

distributer in order to confirm uniform fluidization. The possibility of non-uniform fluidization is quite less in case of CFB boilers, courtesy to the high velocity and highly expanded bed. The multi-orifice nozzle is a popular type of air distributor (Figure 6). Such system contains "n" number of orifices (having diameter $\mathrm{d}_{0}$ ) drilled around a nozzle of much larger diameter $d_{n}$. The size of nozzle is chosen such that its cross section is sufficiently larger than the combined cross-sectional areas of the orifices. This is done to ensure that the fluid resistance across the orifices dominates rather than that across the nozzle [12]:

$$
n \times\left(\frac{\pi}{4}\right) \times d_{0}^{2}<\left(\frac{\pi}{4}\right) \times d_{n}^{2}
$$

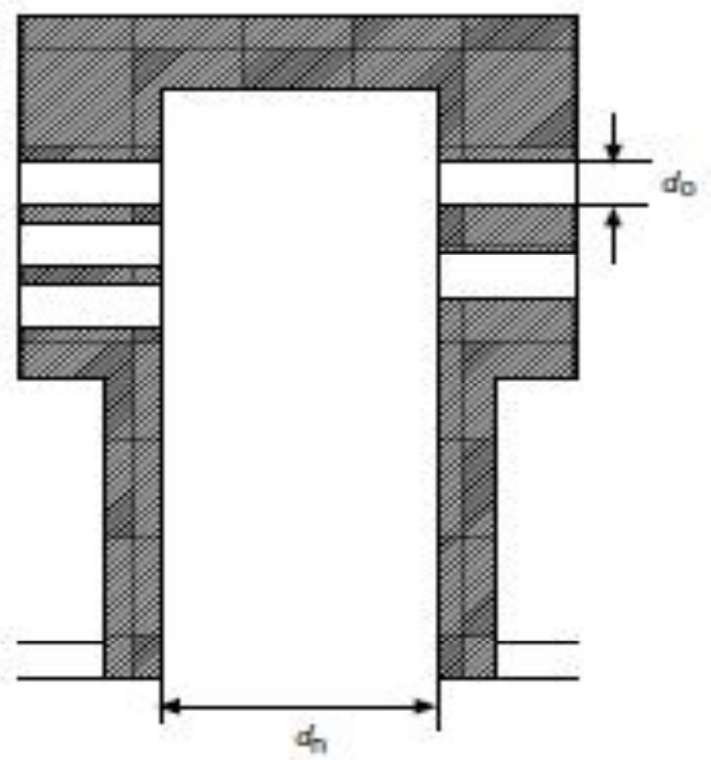

Figure 6. Multi-orifice nozzle on a fluidized bed boiler [10].

If the number of orifices works out to be $n_{t}$; the total number of nozzles is calculated to be [12]:

$$
\begin{gathered}
N_{n}=\left(\frac{2}{\sqrt{3}}\right) \times\left(\frac{1}{P_{n}^{2}}\right) ; \text { For triangular pitch } \\
N_{n}=\left(\frac{1}{P_{n}^{2}}\right) ; \text { For square pitch }
\end{gathered}
$$

\subsection{Computational Fluid Dynamics Analysis for Air Distributors}

Computational fluid dynamics (CFD) is the method of predicting fluid flow, heat transfer, mass transfer, and related phenomena by solving the mathematical equations that governs these processes using a numerical approaches [11]. Simulation of turbulent air flow distribution in CFBC furnace, wherein primary air is entrained through inlet duct system called wind-box, is attempted through state of art CAD/CFD software's. One of the component of CFBC is primary airinlet system to boiler furnace, wherein experience of plant manufacturers concern is mal-distribution of air due to momentum and pressure losses and hence, inefficient combustion and high emission rates. In order to optimize the performance, equal distribution of air to burners is necessary.
So, simple modification can be done for the re-distribution of the air and rectify the current unbalances through the knowledge of the existing flow pattern in primary air-inlet system [5].

\section{Results and Discussions}

\subsection{Selecting Bed Particles}

Bed particle was selected depending on its availability and simplicity in modifying it to suitable diameter. Therefore, sand was selected as bed material. It is available in almost all the river banks and is abundant with various ranges of diameters. So, required size of the sand can be collected by using sieve mechanisms which is easy to use and moreover accurate as well.

\subsection{Selecting Suitable Diameter of the Sand Particles}

Diameter of the sand particles was determined analytically rather than mathematically. Geldart graph was used in determining the diameter of the sand particle. Processes for the selection can be determined by the using graph from figure no 4 . The density difference between sand particle and 
fluid i.e. air is $2646.84 \mathrm{~kg} / \mathrm{m} 3$. Moreover, circulating fluidized bed boiler uses group B materials (ex: sand) so this leaves us with diameter range from (100-500) micrometer. Since we are designing for a small scale CFBC we limited our diameter to 100 micrometer so that we could limit our velocities to minimum as possible.

\subsection{Determination of Different Velocities}

\subsubsection{Minimum Fluidization Velocity}

If the gas-flow rate through the fixed bed is increased, the pressure drop due to the fluid drag continues to rise until the superficial gas velocity reaches a critical value known as the minimum fluidization velocity, Umf. At the velocity where the fluid drag is equal to a particle's weight less its buoyancy, the fixed bed transforms into an incipiently fluidized bed. In this state the body of solids behaves like a liquid. There are different fluidization velocities at different temperatures. The ranges of these velocities were found out. Calculation showed that at $25^{\circ} \mathrm{C}$ velocity was $0.0105 \mathrm{~m} / \mathrm{s}$ and at $825^{\circ} \mathrm{C}$ velocity was $0.00433 \mathrm{~m} / \mathrm{s}$.

\subsubsection{Maximum Amplitude Velocity and Steady Velocity}

The pressure drop across a turbulent bed fluctuates rapidly. As the velocity is increased, the amplitude of fluctuation increases, reaching a peak at the velocity Uc. It then reduces to a steady value as the fluidizing velocity is increased further to the velocity Uk. The transition from a bubbling to turbulent bed does not take place sharply at one velocity. The onset of this transition begins at the velocity Uc and is completed at the velocity Uk. The transition appears to start at the upper surface of the bed and move downward. Result of our calculation showed that maximum amplitude velocity will be $1.23 \mathrm{~m} / \mathrm{s}$ and steady velocity will be $1.93 \mathrm{~m} / \mathrm{s}$ at $25^{\circ} \mathrm{C}$. At $825^{\circ} \mathrm{C}$ maximum amplitude velocity will be $2.58 \mathrm{~m} / \mathrm{s}$ and steady velocity was $4.024 \mathrm{~m} / \mathrm{s}$.

\subsubsection{Terminal Velocity}

It is the velocity attained by the falling particle when the weight of particle is balanced by the drag force. Terminal velocities will be different at different temperatures due to the variation of densities of gas. Our calculations showed that terminal velocity at $25^{\circ} \mathrm{C}$ was $0.823 \mathrm{~m} / \mathrm{s}$ and at $825^{\circ} \mathrm{C}$ was $0.946 \mathrm{~m} / \mathrm{s}$.

\subsection{Design of Wind Box}

The diameter of the wind box is in accordance with the diameter of the boiler which is $0.85 \mathrm{~m}$ i.e. $850 \mathrm{~mm}$ and the length being $420 \mathrm{~mm}$. The diameter of the feed nozzle is determined to be $210 \mathrm{~mm}$. Then the height below the wind box where the feed nozzle is attached is determined. It was found to be $275 \mathrm{~mm}$ i.e. the feed nozzle is located at a distance of $275 \mathrm{~mm}$ below the distributor plate. It also lies in the mid-point of the wind box breadth i.e. $425 \mathrm{~mm}$ from the edge of the wind box.

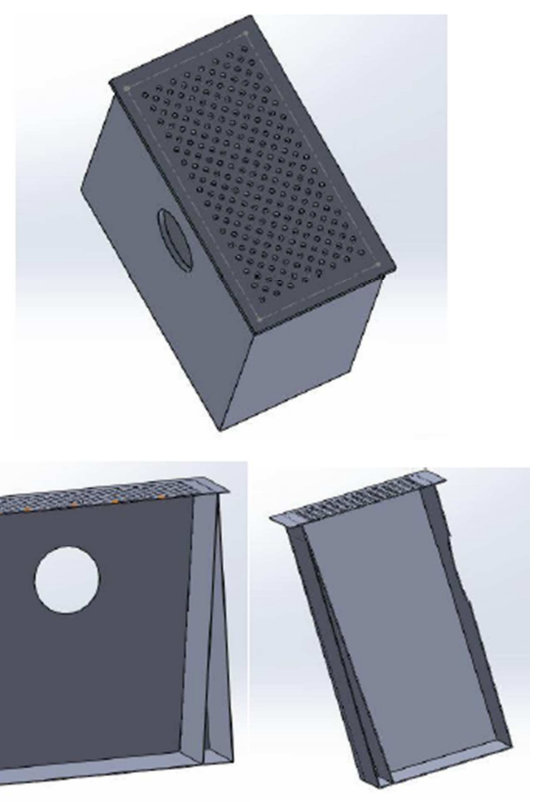

Figure 7. 3D model of Wind Box with sectional views.

\subsection{Design of Air Nozzles}

We use a multi orifice type of air nozzles. Various values were taken for the no of orifices, their diameter and the diameter of the air nozzle. Much iteration was performed and the validity of the design was checked. After much iteration the values were determined as the no of orifices was found out to be 6 , orifice diameter was determined as $3 \mathrm{~mm}$, and finally diameter of air nozzle was found out to be $16 \mathrm{~mm}$.
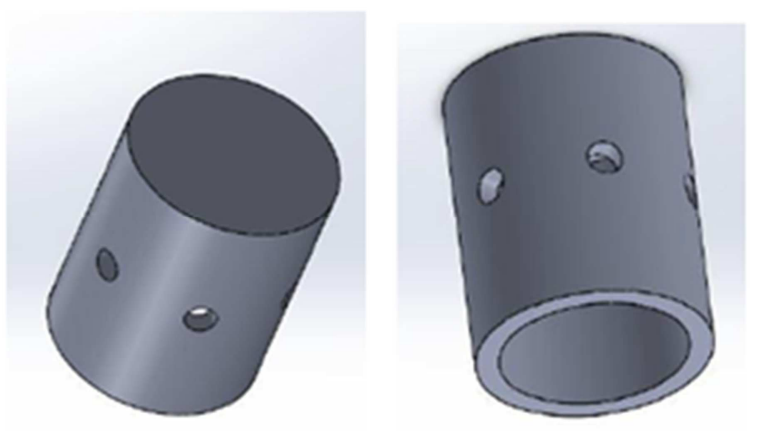

Figure 8. 3D design of Nozzle.

\subsection{Determination of the Pitch and Arrangement of Nozzles (Final Assembly)}

At first the superficial velocity was determined at $1770 \mathrm{C}$ to be $0.85612 \mathrm{~m} / \mathrm{s}$. Then the no of air nozzles in a square meter of a distributor was calculated to be 570.22 . Then the no of air nozzles in the wind box area $\left(0.85^{*} .42\right) \mathrm{m} 2$ were calculated to be nearly equal to be 233 After this the triangular pitch was calculated to be $50 \mathrm{~mm}$. We divided these nozzles into 8 rows of 7 nozzles between which 7 rows of fifteen nozzles are placed. The distance from the center of distributor is taken as $30 \mathrm{~mm}$ thus giving us $15 * 50+2 * 50=850 \mathrm{~mm}$ wind box diameter. Also the lengthwise arrangement was calculated as $7 * 50$ 
$+2 * 35=420 \mathrm{~mm}$. The center to center distance between nozzles of any two rows is $50 / 2=25 \mathrm{~mm}$.

\subsection{Wind Box Simulation in ANSYS-Fluent and Results}

The simulation was carried out in order to find outlet velocity from the outlet nozzles and compare with fluidization velocity that has been calculated from the Excel sheet. If both velocities are similar then the velocity is valid i.e. design is valid. A new geometry where boundary conditions are to be added was created. This geometry is the Boolean of the actual wind-box as it represents the boundary region where air passes throughout the wind-box, from single inlet to 1498 outlets. Wall, outlets and inlet were defined in the geometry. Then an automatic mess was generated. Automatic mesh was selected because the 1498 nozzle holes with just $3 \mathrm{~mm}$ diameter were very small in comparison with $850 * 420 \mathrm{~mm}^{2}$ wind-box.

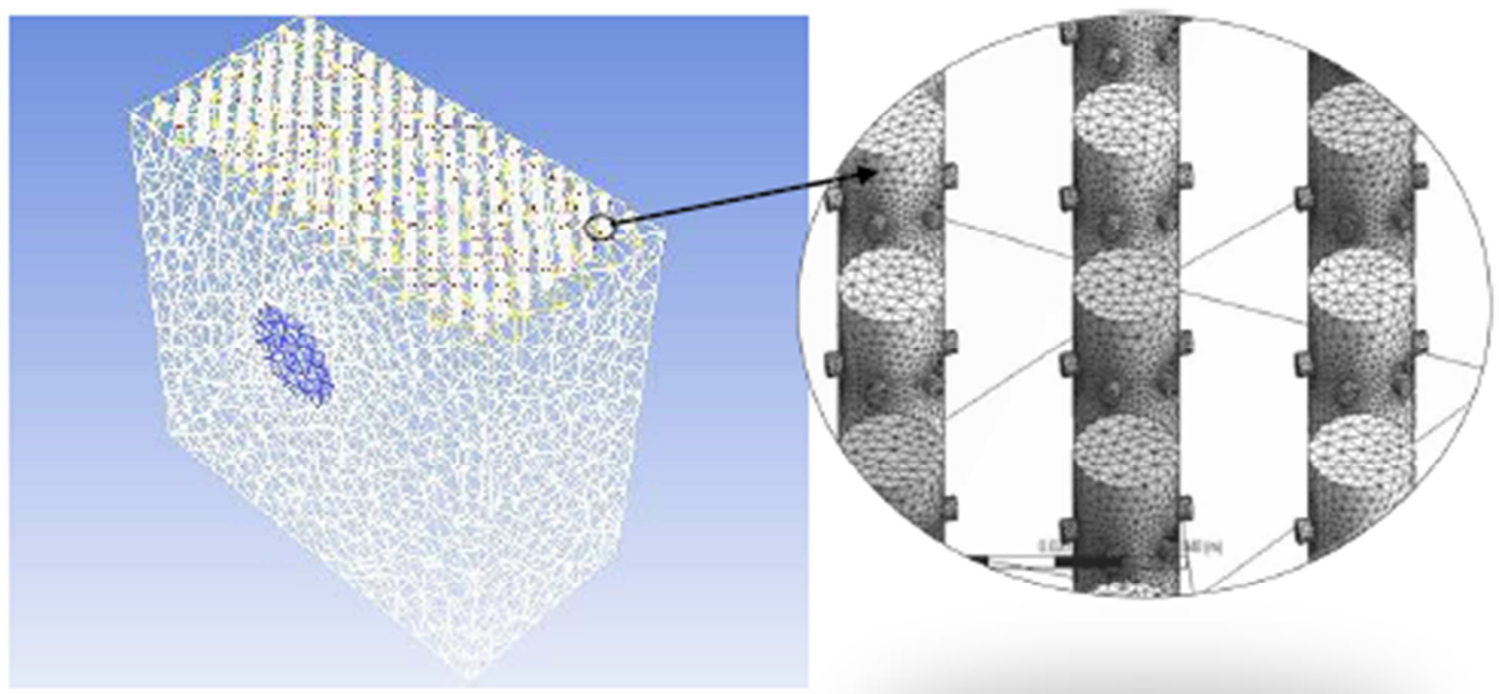

Figure 9. New Mesh to apply Boundary Condition.

\subsubsection{Setup and Assumptions}

- Inlet velocity $=0.428 \mathrm{~m} / \mathrm{s}$ provided by the blower normal to the face, Turbulent Intensity $=5 \%$

- Pressure in wind box $=1 \mathrm{~atm}$

- Energy equation off

- Material=Air

- Cell Zone Condition $=$ Solid

\subsubsection{Results}

The velocity at the outlet of the wind-box (nozzles) ranges from $0 \mathrm{~m} / \mathrm{s}$ at the edge of each nozzle hole to $2.402 \mathrm{~m} / \mathrm{s}$ at the center point of each nozzle hole as shown in figure below. This result shows that the outlet velocity is in the range of fluidization velocity (minimum fluidization velocity $0.7 \mathrm{~m} / \mathrm{s}$ ) and wind-box will be able to perform the fluidization process on the bed materials.

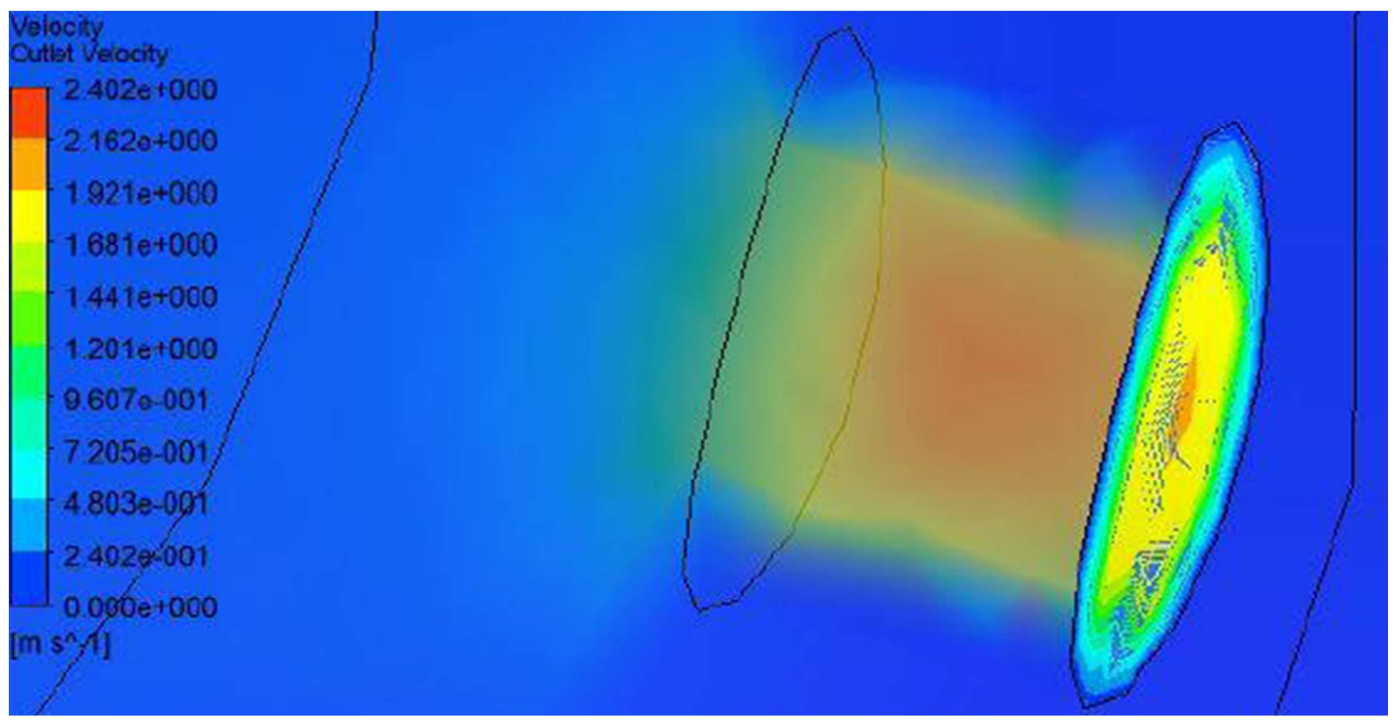

Figure 10. Outlet velocity in the nozzle holes. 


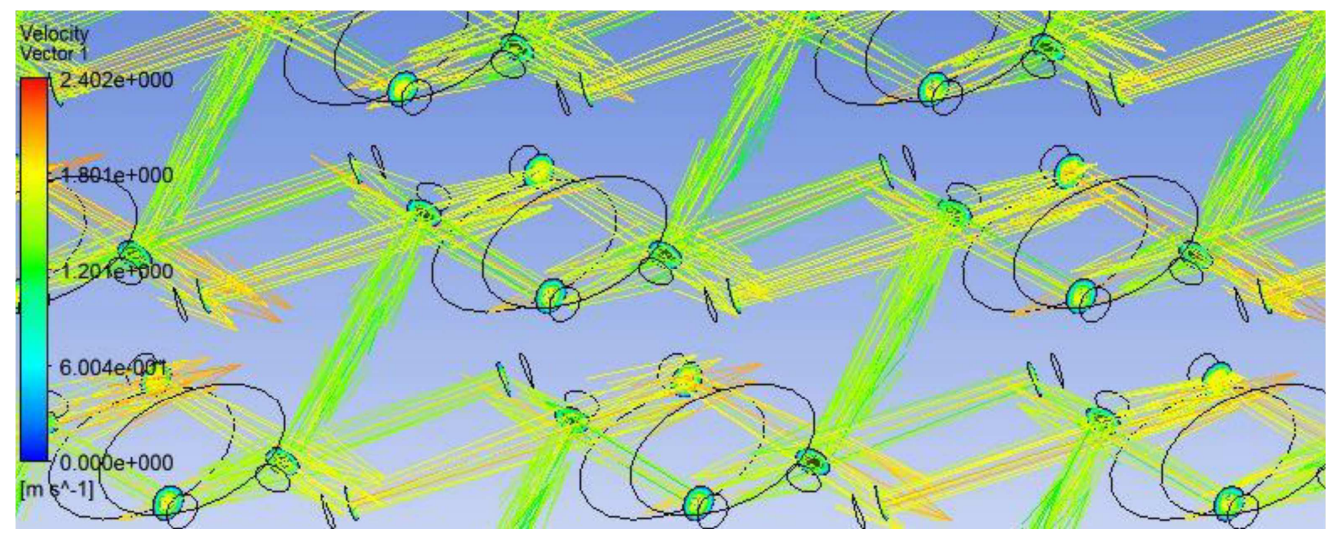

Figure 11. Velocity Vector showing direction of air velocity.

The streamlines result highlights that most of the air that passes through the domain boundary moves directly from the inlet to outlet holes. This is significant and is positive point for the wind-box design. A negligible amount of streamlines flow downwards which eventually reach the nozzles.

There were 1000 equally spaced streamlines that started from inlet, analyzed to provide the result.

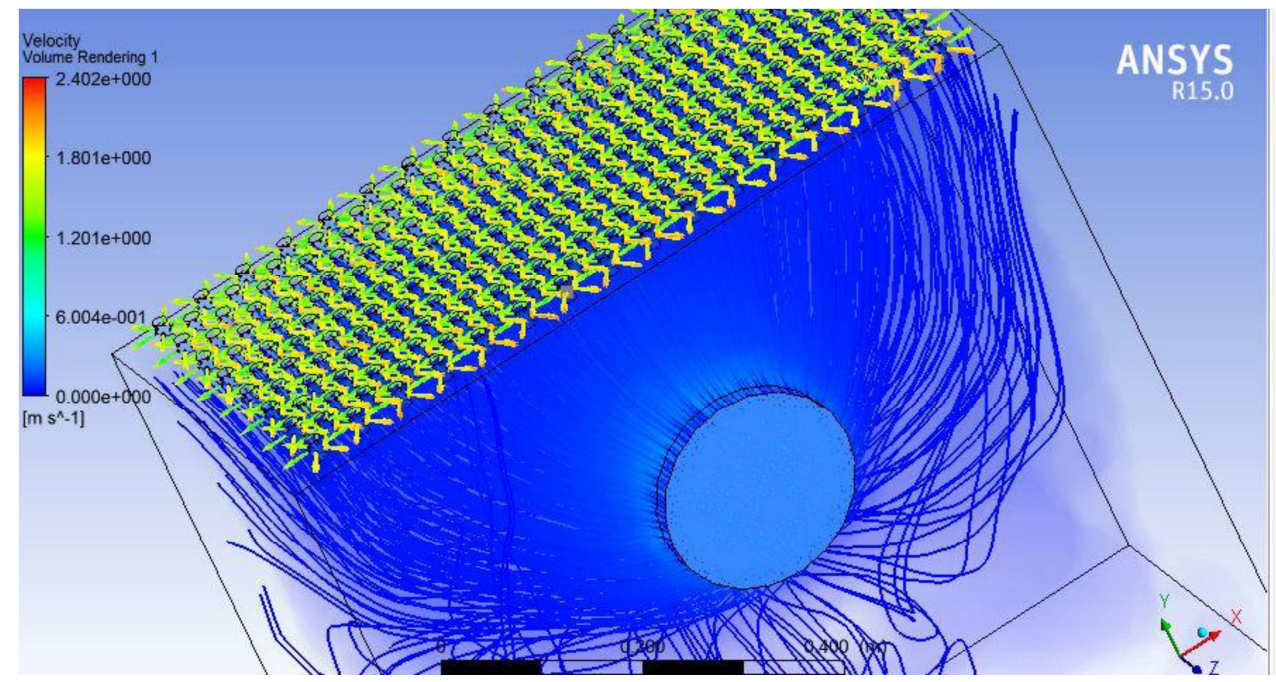

Figure 12. Streamlines and velocity volume rendering result.

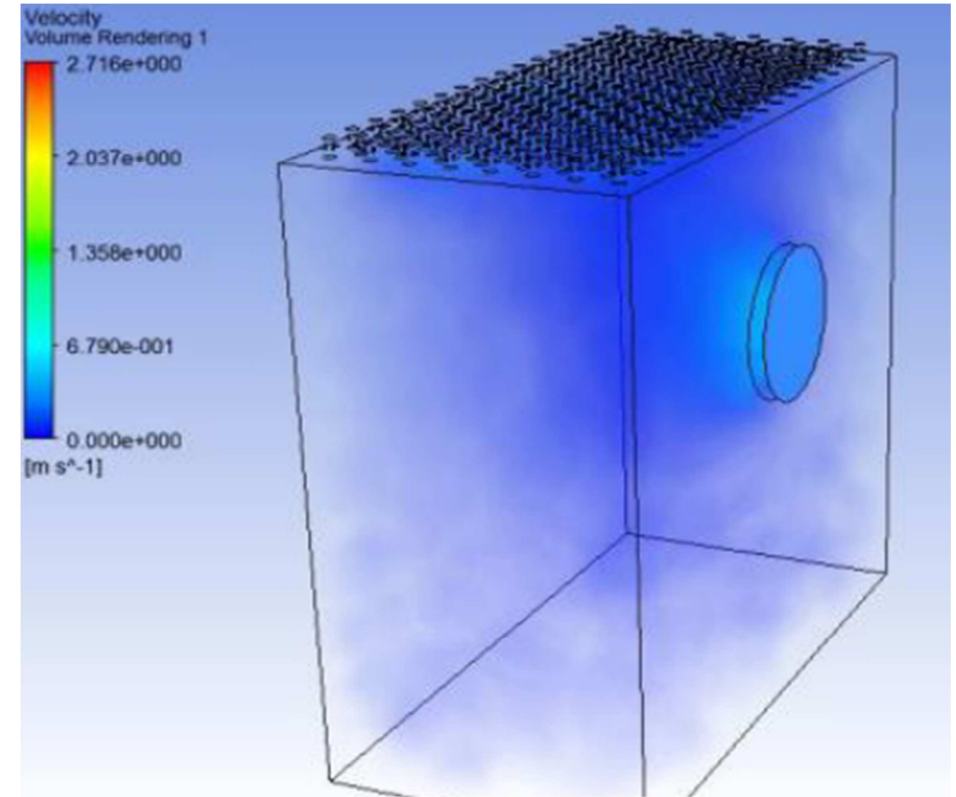

Figure 13. Volume rendering result. 


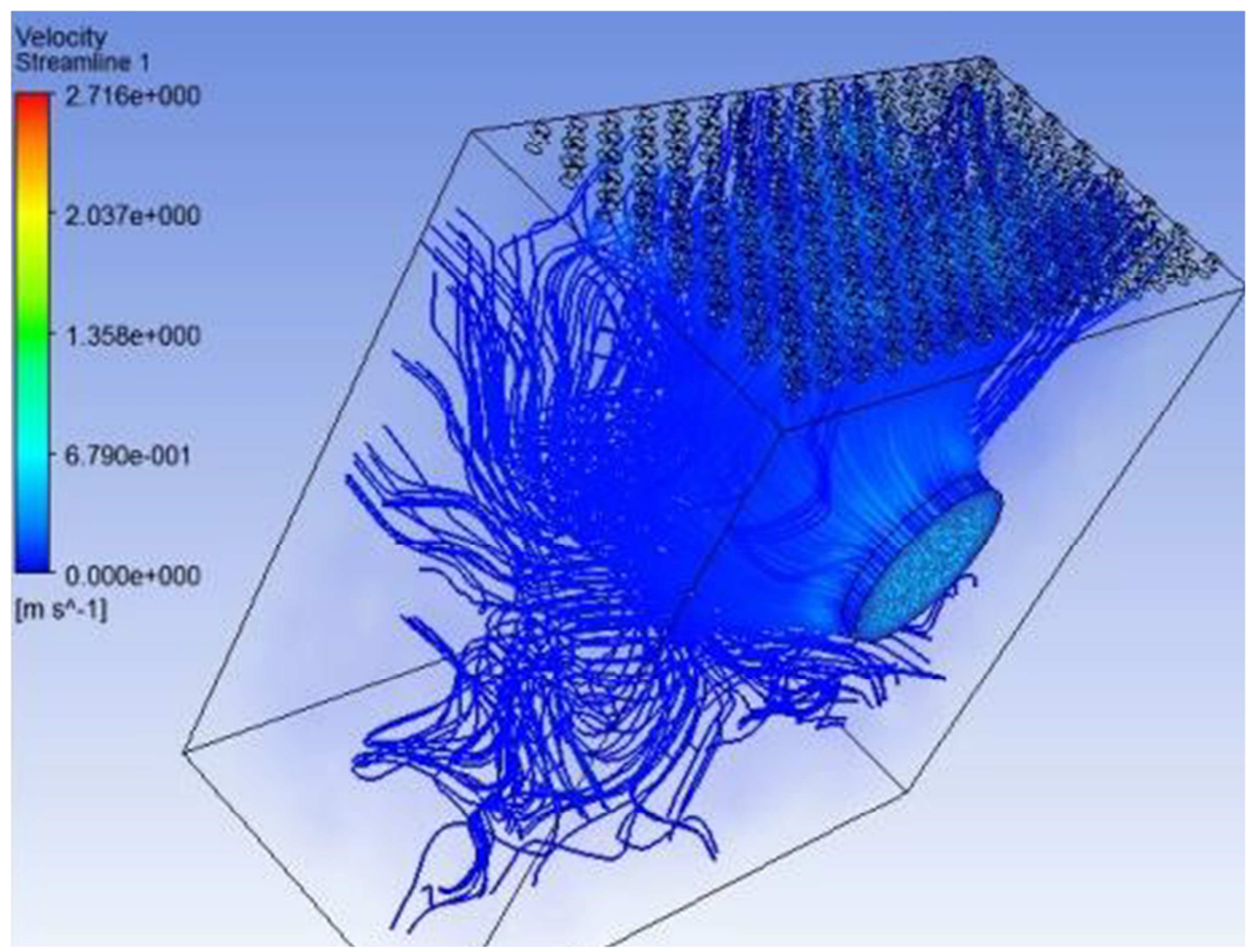

Figure 14. Streamline rendering result.

There is turbulence energy ranging from just $0.00068 \mathrm{~J} / \mathrm{kg}$ to $2.335 \mathrm{~J} / \mathrm{kg}$. These are negligible as a result of laminar flow of the system. The turbulence effect are maximum at the nozzles as shown in Figure 15.

Turbulence Kinetic Energy
Turbuanso
\begin{tabular}{|l|l}
$2.336 \mathrm{e}+000$ \\
$2.102 \mathrm{e}+000$ \\
$1.869 \mathrm{e}+000$ \\
$1.635 \mathrm{e}+000$ \\
$1.402 \mathrm{e}+000$ \\
$1.168 \mathrm{e}+000$ \\
$9.348 \mathrm{e}-001$ \\
$7.013 \mathrm{e}-001$ \\
$4.677 \mathrm{e}-001$ \\
$2.342 \mathrm{e}-001$ \\
$6.869 \mathrm{e}-004$
\end{tabular}
[J kg*-1]

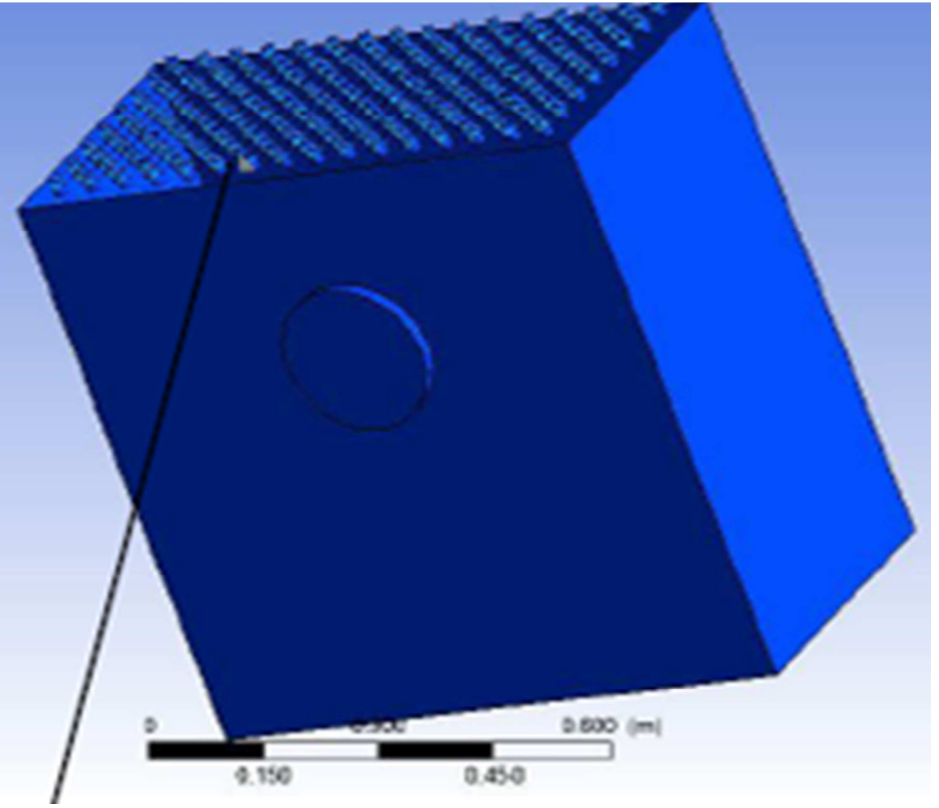

Figure 15. Turbulence Kinetic energy.

The wall shear caused by the air was also analyzed. The maximum wall shear is at nozzle holes which is still low at just 5.1*10-1 Pa. The design of the wind-box and nozzles pattern easily withstands the wall shear and can be neglected. 


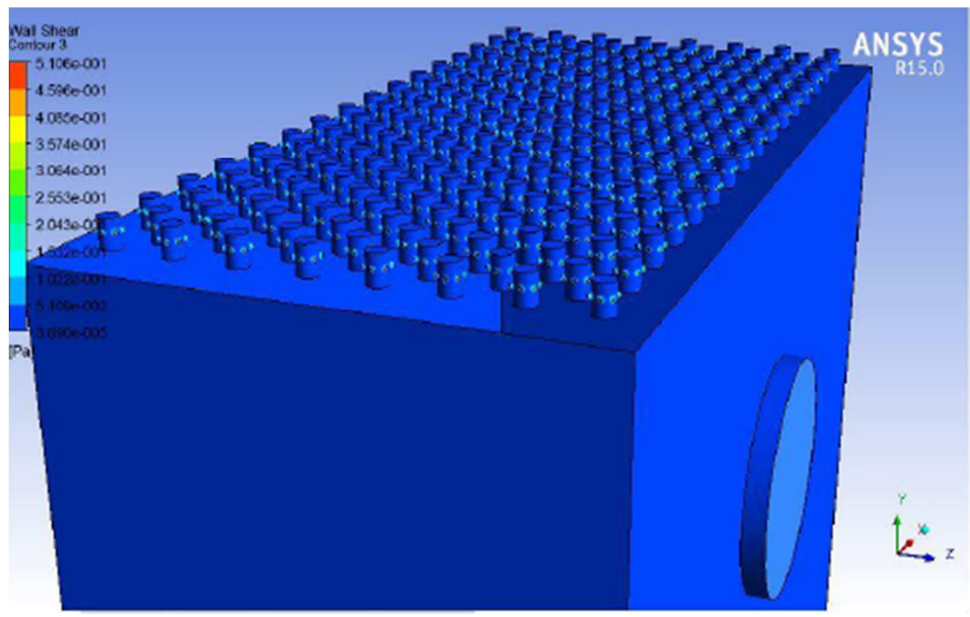

Figure 16. Wall shear caused by air.

\subsubsection{Results in Modified Wind-Box}

A new modified geometry and mesh was created. The walls are chamfered to an angle of 30 degrees instead of straight wall in previous design. Though the wall in which inlet was present remains unchanged. Wall, outlets and inlet were defined in the geometry. Then an automatic mesh was generated.

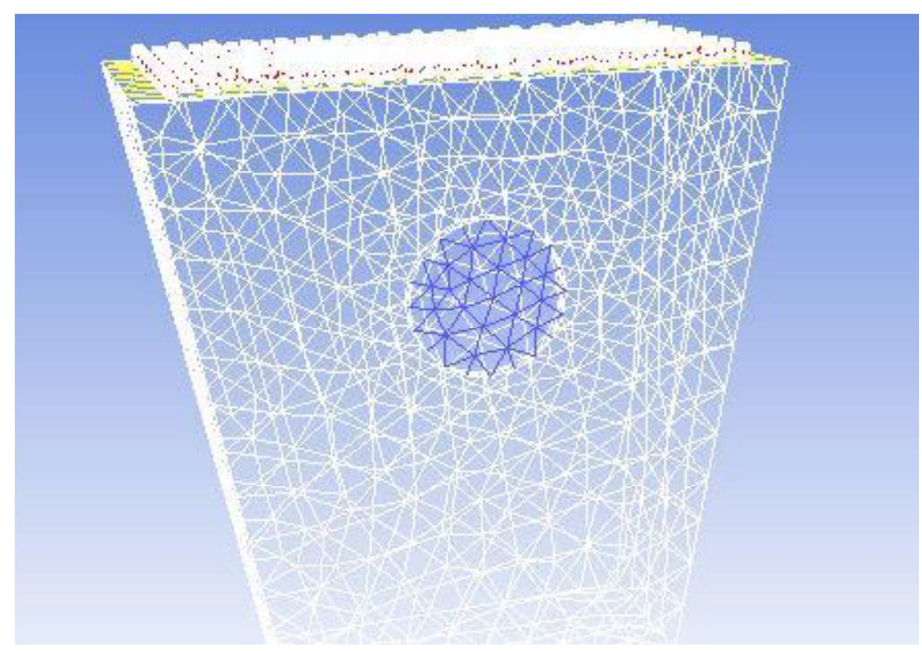

Figure 17. Modified geometry meshing.

The velocity at the outlet of the wind-box ranges from $0 \mathrm{~m} / \mathrm{s}$ at the edge of each nozzle hole to $2.243 \mathrm{~m} / \mathrm{s}$ at the centre point of each nozzle hole as shown in figure below. The velocity is above minimum fluidization velocity so fluidization occurs.

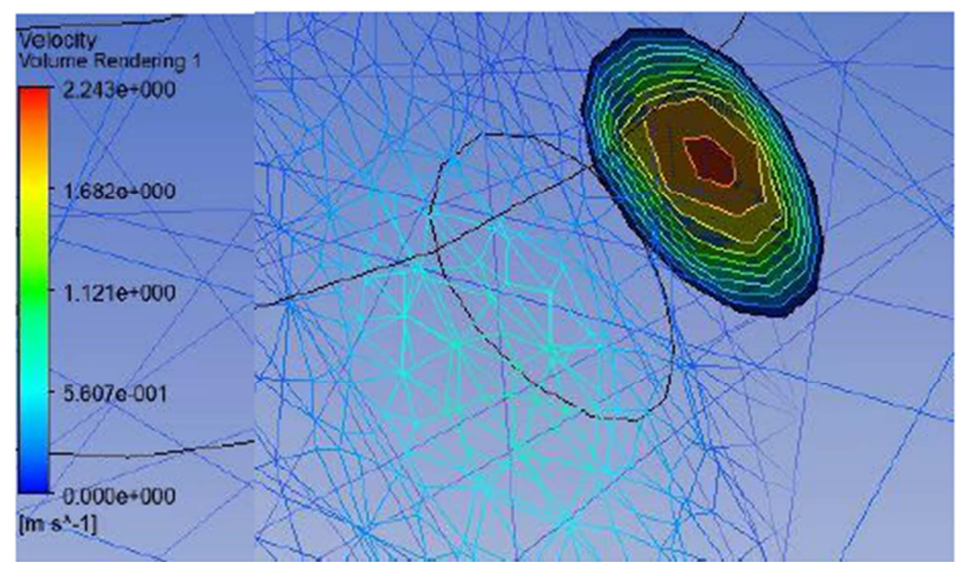

Figure 18. Velocity in nozzle(outlet). 


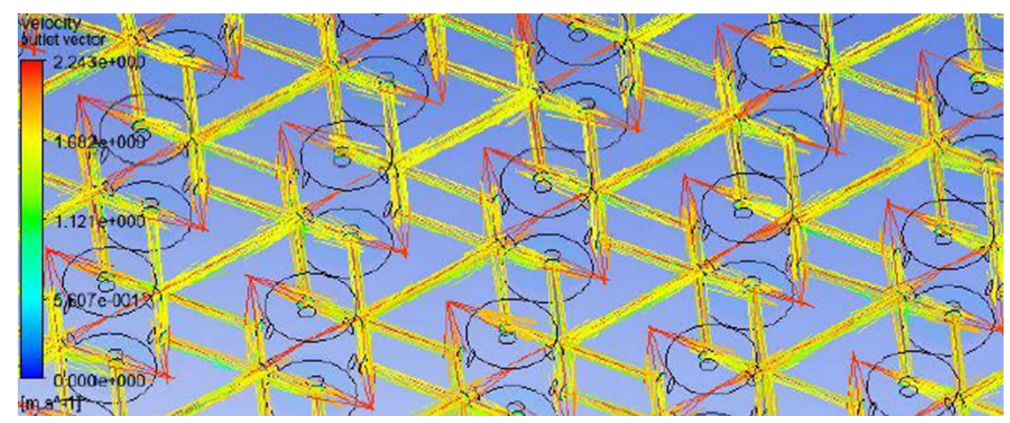

Figure 19. Velocity vector showing direction and speed of air.

The maximum velocity may be less than in previous design (straight wall), but the average velocity within a nozzle is more than in previous design. This is a positive result.

The main improvement caused by this modification is the flow of air from inlet to outlet. All the 2500 streamlines that were examined during the simulation reached the outlet holes without much deviation than in the previous wind-box. Few streamlines that went at bottom face of the wind-box circled towards the outlet. This pattern was rarely shown by streamlines in previous wind-box.

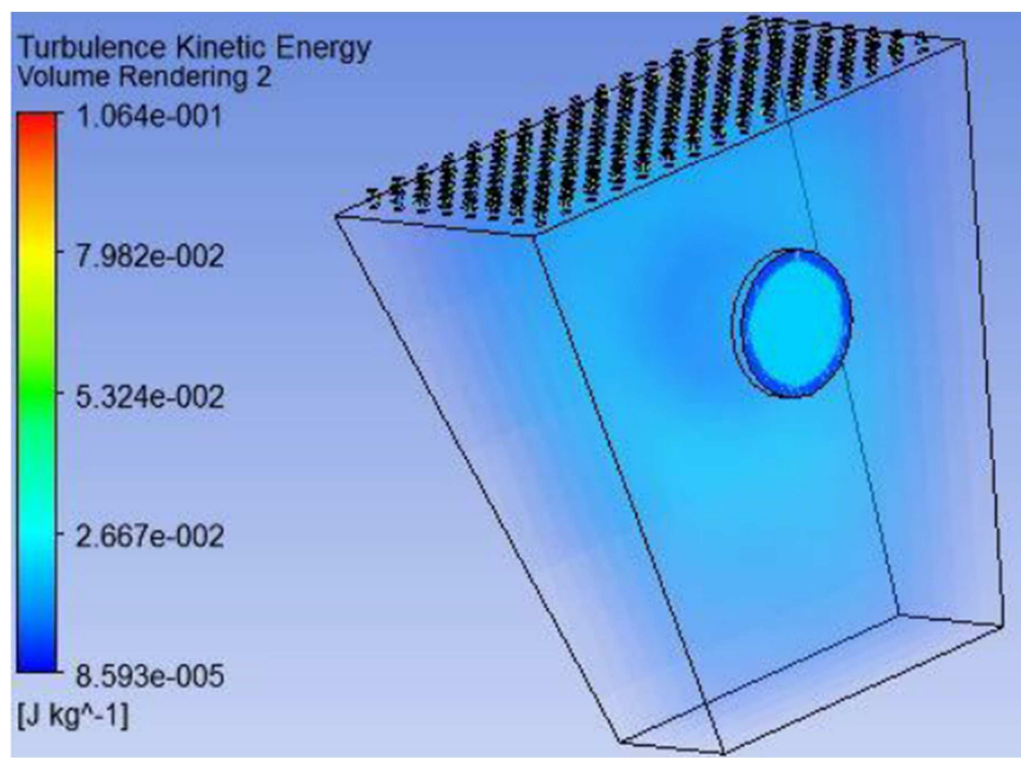

Figure 20. Turbulence Kinetic energy increase but still negligible.

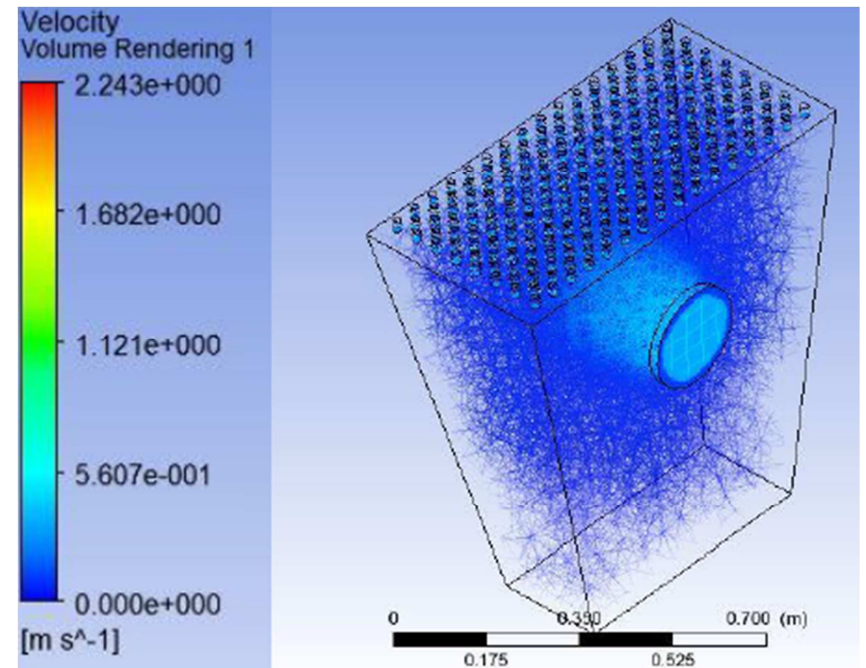

Figure 21. Velocity volume rendering result. 


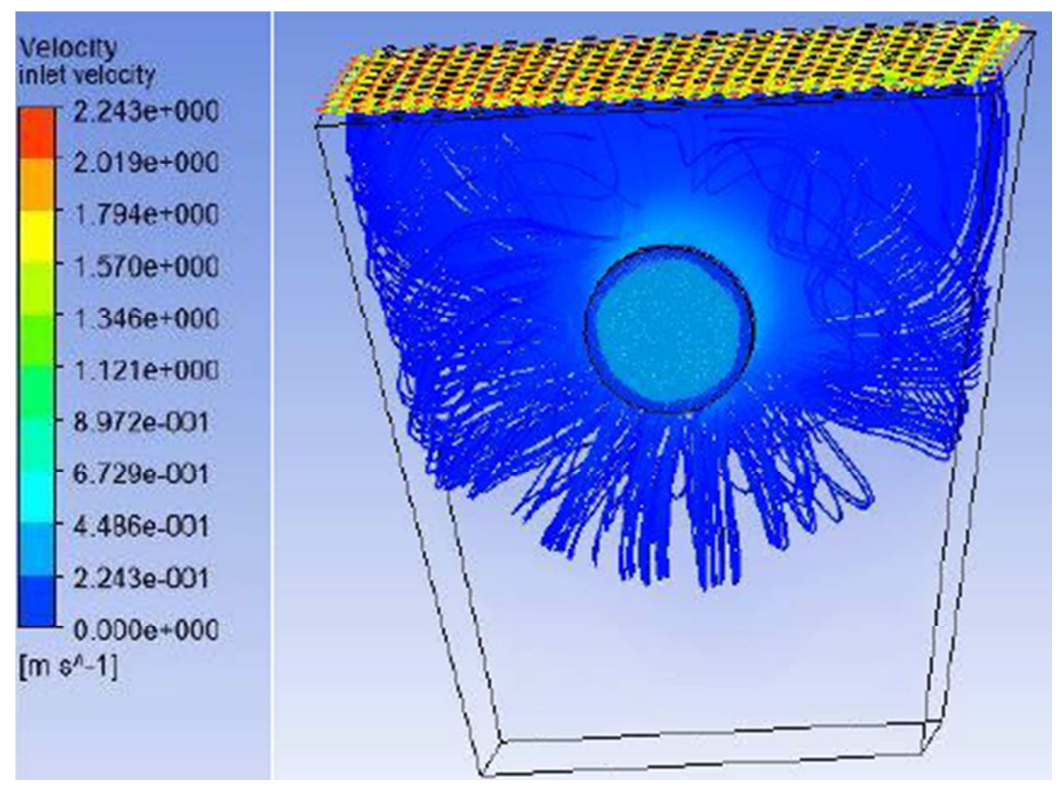

Figure 22. Velocity vector showing direction and speed of air.

\subsection{Sand Particle Distribution Inside Combustion Chamber}

For the calculation of these results following methods has been used:

- Solver method: Pressure Density;

- Model: Multiphase Eulerian Method;

- Number of Eulerian phase: 2 (Air, Sand);

- Phases: Air (Primary), Sand (Secondary);

- Air: velocity $2.24 \mathrm{~m} / \mathrm{s}$;

- Sand: velocity $0 \mathrm{~m} / \mathrm{s}$
Following result in figure 23 is the volume fraction of sand observed during fluidizing phenomena. Maximum fraction of sand has been fluidized while little fraction of sand remains on the plate. Red contour line represents fraction of sand stationary on the plate while other contours represents the fraction of sand moving with certain velocity. From the result we could conclude that velocity generated from calculation fluidizes the given sand particles. Outlet velocity of $2.24 \mathrm{~m} / \mathrm{s}$ has yielded following result which matches with the design criteria.
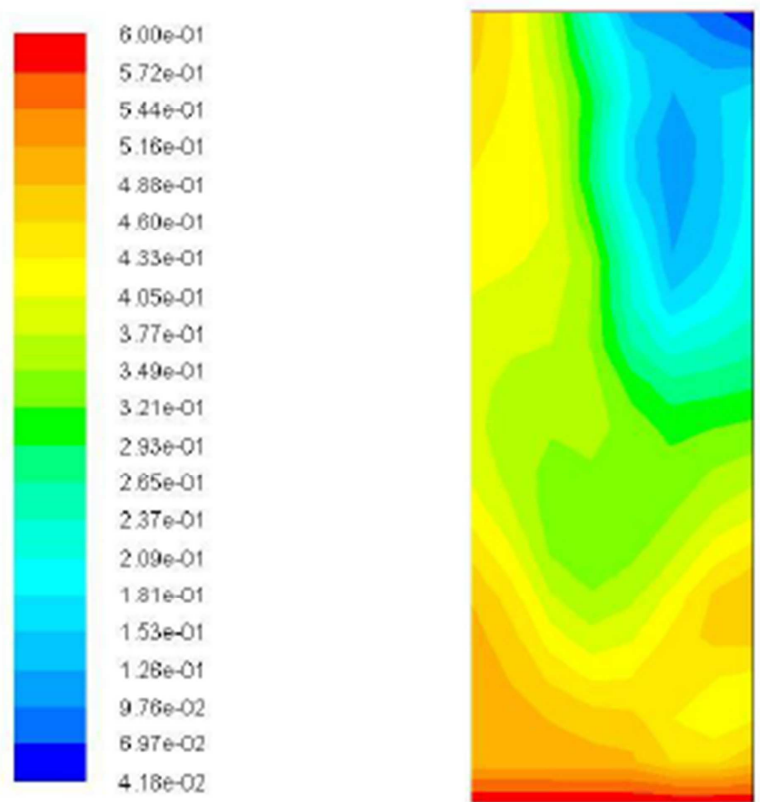
Following result in figure 24, represents the distribution of air particles inside the combustion chamber due to the velocity provided by the air distributor. Provided velocity is $2.24 \mathrm{~m} / \mathrm{s}$. From this result it is clear that air fraction is minimum in the region where volume fraction of sand is maximum. Due to the space occupied by sand in the bottom, fraction of air is reduced to minimum. Maximum air fraction can be observed in the upper region where sand particles do not reach due to action of gravity.
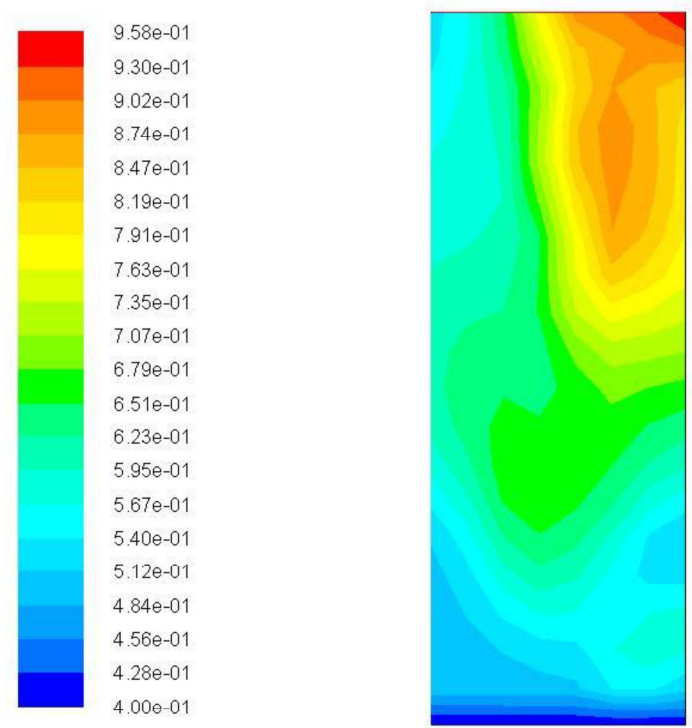

Contours of Volume fraction (air)

Figure 24. Volume fraction of air in combustion chamber.

\subsection{Simulation of Wind-Box in Static Structural}

Static Structural solver is a tool which provides user to calculate the static loading and its impact in a design. It provides necessary templates for providing input such as forces, pressure, stress, moment and uniformly distributed load. The project requires a testing for the strength of the design. So, static structural solver was used to perform the strength test on the design. Necessary forces, line pressure, pressure and moment was applied on the design by using ANSYS Static Structural.

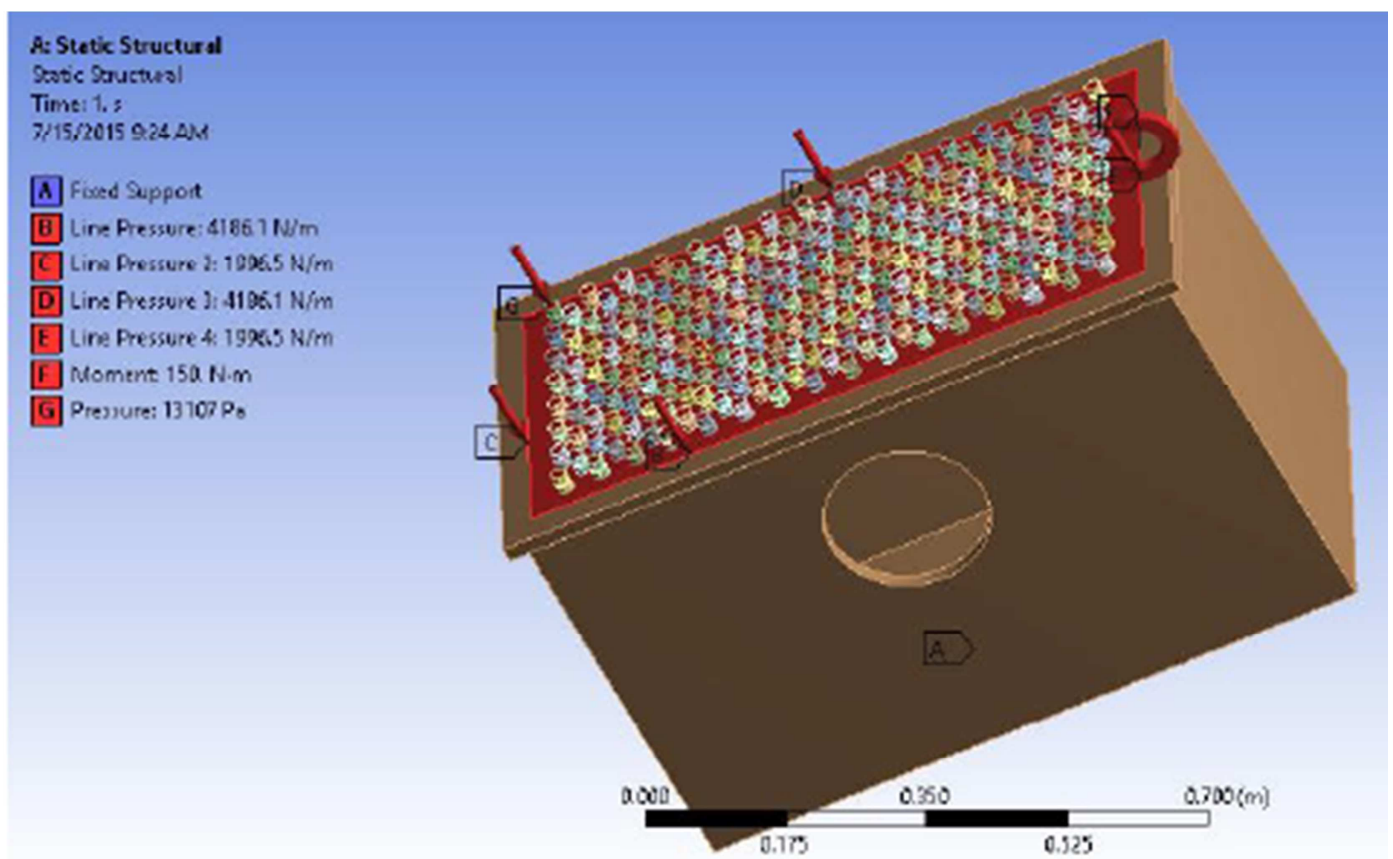

Figure 25. Forces and moment acting in the wind box. 
Following forces were applied on the surface of the model. Lower plane was fixed which is denoted by A. B, C, D and E are the uniformly distributed load around the perimeter. $\mathrm{F}$ indicates the moment created due to the weight of the cyclone. $G$ indicates the pressure over the surface due to the weight of sand particles. Above image shows the force distribution along with its magnitude.

Following simulation result in figure 26 indicates the static structural analysis of stress exerted in the air distributor model. Maximum stress is exerted on the upper mid side of the model. Maximum stress is $4.5866 * 106 \mathrm{~Pa}$ which is indicated by a red contour line in the figure. Minimum stress is indicated by blue contour whose stress value is $295.64 \mathrm{~Pa}$. From this analysis it is concluded that deflection at the point of maximum stress. So, necessary attention should be paid at that point. Stress concentration is reasonably high around the hole due to its low stress area. Maximum concentration in the upper mid portion is due to the weight of sand. Slight concentration of stress in the upper right side is due to the moment created by weight of the cyclone.

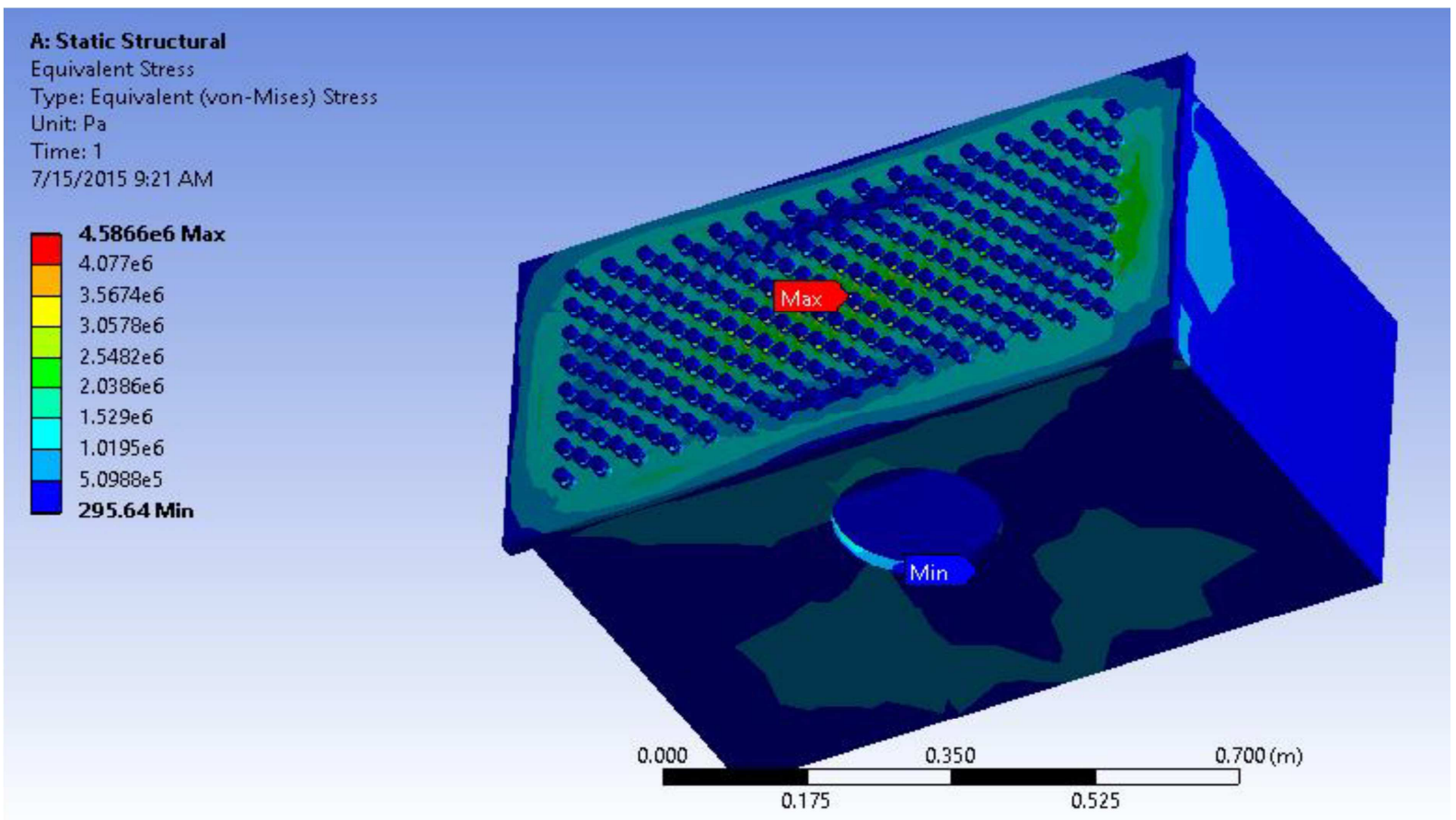

Figure 26. Equivalent stress in wind box.

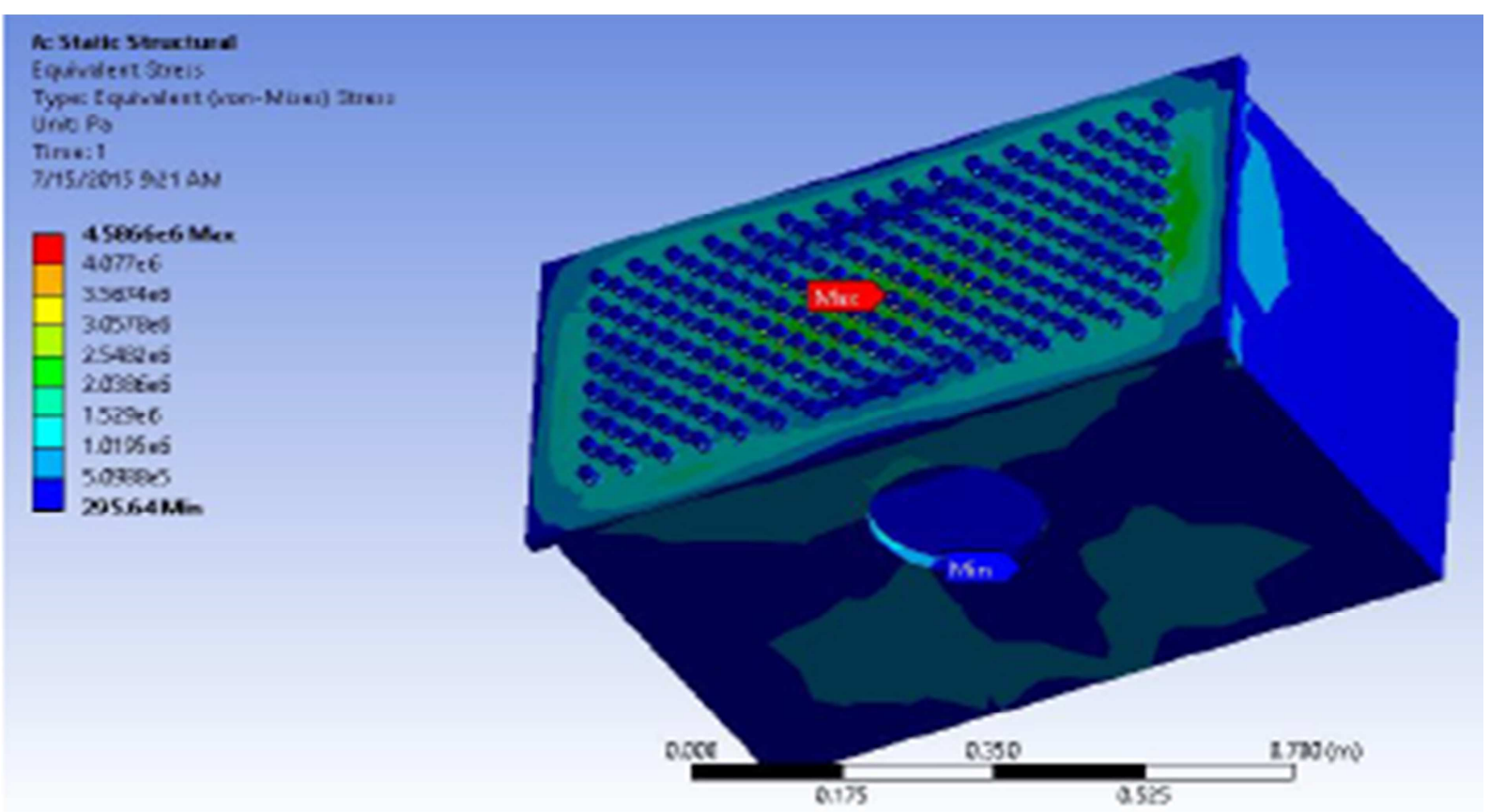

Figure 27. Forces and moment acting in the wind box. 
The simulation image in figure 27 is about the total deformation obtained when combustion chamber is attached above the given model. There is no significant deformation on the model when the wind box is acted upon by the weight of the combustion chamber and sand. Moreover, the deflection of $2.3032 * 10-6 \mathrm{~m}$ is due to the slight pressing of wind box due to the weight of combustion chamber. There is concentration of deformation contour on the mid portion of the model. It is due to the added weight of the sand above the wind box.

The design is appropriate to hold the combustion chamber. Strength according to the result is within the range to handle the weight and moment created by combustion chamber and cyclone.

\section{Conclusions and Recommendation}

Firstly, complete air distributor system for the circulatory fluidized bed boiler was designed. Sand was selected as the bed material for the fluidizing phenomena. Diameter of the sand was determined and was found to be 385 microns.

Secondly, parameters required for constructing a wind box was generated by coding in MS-Excel. Number of nozzles, arrangements of nozzles, diametric pitch, dimensions of the wind box and dimensions of the inlet were generated. Numbers of air distributors were 233. Each air distributor contained 6 air nozzles. Air Nozzles were arranged in triangular pitch which resulted in 1398 number of nozzles. Dimension of the wind box was $850 \mathrm{~mm}$ X $420 \mathrm{~mm}$.

Furthermore, structural integrity of the design was performed using ANSYS Static Structural. Result from these simulation showed that the design was correct. No deformations were observed in the design. There were traces of stress concentration near the inlet zone. It was due to the less stress area near the inlet. Moment created due to the cyclone had negligible effect on the design due to its low weight.

Sand had to be considered in the design due to its large weight. Moreover, Computational Fluid Dynamics (CFD) was done using FLUENT. Simulation on distribution of air inside the wind box showed that all the streamline converged at the outlet which concludes that velocity calculated theoretically using various formulas were correct.

Lastly, the two phase simulation on distribution of air and sand particles inside combustion chamber were performed. Results indicated that with the provided velocity sand was fluidized at optimum rate. Fraction of sand particles resided on the base while remaining sand were fluidized and was recovered using cyclone. Air volume fraction was found to be minimum at the base where sand was maximum and was found to be maximum where sand volume fraction was minimum.

Though this research has incorporated all the design parameters required to construct a wind box system for a circulatory fluidized bed boiler, from the observations of the work following recommendations are suggested:

- Secondary air distribution system can be added to the designed system for more inlet air. This helps in complete combustion of the fuel.

- Lower part of wind box must be filleted so that all the incoming streamlines would converge at the outlet of the nozzle.

- Truss could be arranged around the inlet hole to remove excessive stress concentration in the region.

\section{References}

[1] "Independent Statistics and analysis: Energy Information Administration," 30 may 2013. [Online]. Available: $\mathrm{http}: / /$ www.eia.gov/countries/country-data.cfm?fips=np.

[2] W. Podolski, "Pressurised FBC Technology," 1983.

[3] A. M. Squires, "The story of fluid catalytic cracking, In Circulating Fluidized Bed Technology," Pergamon Press, Toronto, 1986.

[4] J. R. Howard, "Fluidized Beds - Combustion and Applications," 1983, p. 131.

[5] L. Reh, "Circulating Fluidized Bed Technology-VI," in Challenges of circulating fluid bed reactors in energy and raw materials industries, 1999, p. 10-11.

[6] K. Kuhle, "Zement-Kalk-Gips," 1984, pp. 34, 219-225. 4.

[7] Jun Su, "DESIGN AND OPERATION OF CFB BOILERS," 20th Conference on Fluidized Bed Combustion, 2009.

[8] D. M. Considine, Energy Technology Handbook, 1977.

[9] N. Yoshida, K. Yamamoto, T. Iwasaki and lida, "NKKfluidized bed," 1991, NKK Technical Report.

[10] Feng, Circulating Fluidized Bed Combustion Boiler, Beijing: Electric industrial Press, 2003.

[11] C. Bhasker, "Simulation of air flow in the typical boiler windbox segments," Advances in Engineering Software, 2002.

[12] P. Basu, Combustion and Gasification in Fluidized Beds, Taylor and Francis Group, 2006.

[13] "CFD - Computational Fluid Dynamics," [Online]. Available: http://www.cfd.com.au/. 